\title{
Outcomes of platelet-rich plasma for plantar fasciopathy: a best-evidence synthesis
}

\author{
Tao Yu ${ }^{\dagger}$, Jiang Xia ${ }^{\dagger}$, Bing Li', Haichao Zhou, Yunfeng Yang ${ }^{*}$ and Guangrong Yu
}

\begin{abstract}
Background: Plantar fasciopathy (PF) is a very common disease, affecting about 1/10 people in their lifetime. Platelet-rich plasma (PRP) had been demonstrated to be useful in achieving helpful effects for plantar fasciopathy. The purpose of this study was to compare the pain and functional outcomes between PRP and corticosteroid (CS) or placebo for plantar fasciopathy through meta-analysis and provide the best evidence.
\end{abstract}

Methods: Literature was searched systematically to explore related studies that were published in Cochrane Library, PubMed, Embase, Medline, SpringerLink, OVID, and ClinicalTrials.gov. Articles regarding comparative research about the outcomes of PRP therapy and CS or placebo injection were selected. Data of pain and functional outcomes was extracted and imported into Reviewer Manager 5.3 to analyze.

Results: Thirteen RCTs were included and analyzed. Analysis results showed significant superiority of PRP in outcome scores when compared with CS (VAS: MD $=-0.85, P<0.0001, P^{2}=85 \%$; AOFAS: MD $=10.05, P<0.0001$,

$P^{2}=85 \%$ ), whereas there is no statistical difference in well-designed double-blind trials (VAS: MD $=0.15, P=0.72$,

$P^{2}=1 \%$; AOFAS: MD $=2.71, P=0.17, P=0 \%$ ). In the comparison of the PRP and the placebo, the pooled mean difference was $-3.76(P<0.0001,95 \% \mathrm{Cl}=-4.34$ to -3.18$)$.

Conclusions: No superiority of PRP had been found in well-designed double-blind studies, whereas it is implied that the outcomes of PRP are better than placebo based on available evidence.

Keywords: Platelet-rich plasma, Corticosteroid, Fasciopathy, Therapy

\section{Background}

Plantar fasciitis (PF) is a very common disease, affecting about $1 / 10$ people in their lifetime and subsequently affected the quality of life [1]. A variety of treatments had been carried out for plantar fasciopathy, including orthoses $[2,3]$, shockwave therapy $[4,5]$, drug medication [6], stretching exercise [7, 8], laser therapy [9], taping [10], and percutaneous injection [11]. But PF is difficult to cure completely.

\footnotetext{
*Correspondence: Ibzlq@163.com; yangyunfeng1051@126.com

${ }^{\dagger}$ Tao Yu and Jiang Xia contributed equally to this work.

Department of Orthopedic Surgery, Tongji Hospital, Tongji University School of Medicine, Shanghai 200065, China
}

Platelet-rich plasma (PRP) is most concisely defined as a volume of plasma that contains a concentrate of platelets above that of baseline blood levels [12]. In recent years, the role of PRP in the treatment of PF has drawn wide attention [13-19]. However, the advantages of PRP in modern treatment for PF have not been fully confirmed, and different randomized controlled trials have drawn inconsistent conclusions when comparing the use of PRP with CS or placebo $[20,21]$. The method of injecting corticosteroids (CS) is another common treatment that has proven to be effective $[22,23]$, but it has some limitations at the same time. Some studies $[24,25]$ have

(c) The Author(s). 2020 Open Access This article is licensed under a Creative Commons Attribution 4.0 International License, which permits use, sharing, adaptation, distribution and reproduction in any medium or format, as long as you give appropriate credit to the original author(s) and the source, provide a link to the Creative Commons licence, and indicate if changes were made. The images or other third party material in this article are included in the article's Creative Commons licence, unless indicated otherwise in a credit line to the material. If material is not included in the article's Creative Commons licence and your intended use is not permitted by statutory regulation or exceeds the permitted use, you will need to obtain permission directly from the copyright holder. To view a copy of this licence, visit http://creativecommons.org/licenses/by/4.0/ The Creative Commons Public Domain Dedication waiver (http://creativecommons.org/publicdomain/zero/1.0/) applies to the data made available in this article, unless otherwise stated in a credit line to the data. 
reported that different injection sites can produce pain of different lengths. On the other hand, this method may also lead to some complications, such as rupture of the plantar fascia and pad atrophy.

The systematic review of the validity of PRP and CS in the previous literature is inconsistent. Many literatures [26-29] indicate that the efficacy of PRP is significantly better than that of CS, but the reliability of these conclusions is affected to some extent by research selection strategies, statistical methods, and interference factors, such as limited number of trials. Thus, the aim of our systematic review was conducted to assess the efficacy of PRP for PF in terms of pain and functional outcomes. We performed the best comprehensive analysis of the evidence for the previous RCT. To ensure a more accurate conclusion as a means of guiding clinical decision-making, we combined and quantified PRP with CS or placebo for PF on clinical results.

\section{Material}

\section{Literature search and study selection}

Our systematic review of RCTs was produced to identify all of the published data on PRP used in PF according to the Cochrane Collaboration guidelines and bestevidence synthesis principles. The following processes are completed by two independent auditors. If no agreement can be reached through negotiation, another auditor will make the final decision. This study complies with the PRISMA guidelines, and all the information required was reported.

The databases retrieved include Cochrane Library, PubMed, Embase, Medline, SpringerLink, OVID, and ClinicalTrials.gov in December 2019. The following search terms were used: Plantar Fasciitis or Plantar Fasciopathy or PF, Platelet-Rich Plasma or PRP, Corticosteroid or CS, Randomized controlled trials or RCTs, and Intra-articular injection or IA injection.

The inclusion criteria of the studies are as follows: (1) must be RCT; (2) ensure at least 20 participants; (3) all participants are followed for at least 1 month; (4) use plantar fascia thickness (PFT) quantitative scores such as visual analog scale (VAS), tenderness threshold (TT), and heel tenderness index (HTI) which are used to assess pain, function, etc., as well as foot function index (FFI); (5) no more than $20 \%$ of participant loss occurred in follow-up; and (6) the article language must be English and the full text is available.

\section{Data extraction}

The following data were extracted from included studies: study design, study population type, age, number of cases, and interventions. Any disagreements in data extraction were dealt with discussion and determined by a third researcher. Pain and function scores such as VAS, PFT, HTI, TT, and FFI were recorded at each visit. The mean and standard deviation (SD) was estimated with the following formula when it was not available in some included studies: $\mathrm{SD}=\sqrt{ } n \times\left(P_{97.5}-P_{2.5}\right) /[2 \times(=\operatorname{tin} \mathrm{v}(1-0.95, n-$ 1))]. $P_{97.5}$ and $P_{2.5}$ represented percentiles, and $n$ was the number of the cases.

\section{Quality and risk of bias assessments}

Two independent authors were responsible for reviewing all articles and rated the articles as "high," "low," or "unclear" based on the following: performance bias, detection bias, wear bias, reported bias, and other deviations. Any differences must be discussed for consensus. If no agreement can be reached, the third investigator must be consulted. A study of high quality should have appropriate distribution concealment, adopt a double-blind design, and report complete results data, and the experiment is considered to have a lower risk of bias [30, 31].

\section{Statistical analysis}

RevMan 5.3.5 was used to analyze numerical data for included trials. For binary data, risk ratio (RR) and 95\% confidence interval $(\mathrm{CI})$ assessment test criteria were used $(a=0.05)$. For continuous data, the SD in the meta-analysis was combined into a weighted mean difference (WMD) and a 95\% CI. The heterogeneity was tested by $I^{2}$ statistic. The heterogeneity was considered low when $I^{2}$ statistic was $25-50 \%$. The heterogeneity was moderate when $I^{2}$ statistic was $50 \sim 75 \%$, and the heterogeneity was high with $I^{2}$ statistic $>75 \%$. The sensitivity analysis was performed when the $I^{2}$ statistic was $>50 \%$. The difference was considered significant when the $P$ value was $<0.05$.

\section{Results \\ Description of studies and demographic characteristics}

A total of 854 articles have been identified as potential correlation studies, as shown in Fig. 1. A total of 25 complete publications were screened after screening titles and abstracts $(n=182)$ and deleting copies $(n=$ 649). Then, a comprehensive evaluation of 25 complete manuscripts was carried out, which further excluded the other 12 studies, and the remaining 13 studies were included. Of the 13 articles, 11 compared PRP and CS, with placebo (saline) as a control. Characteristics of the included studies are shown in Table 1. The classification of PRP was applied using the method described by Dohan Ehrenfest et al. [44]. 


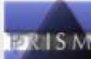

PRISMA 2009 Flow Diagram
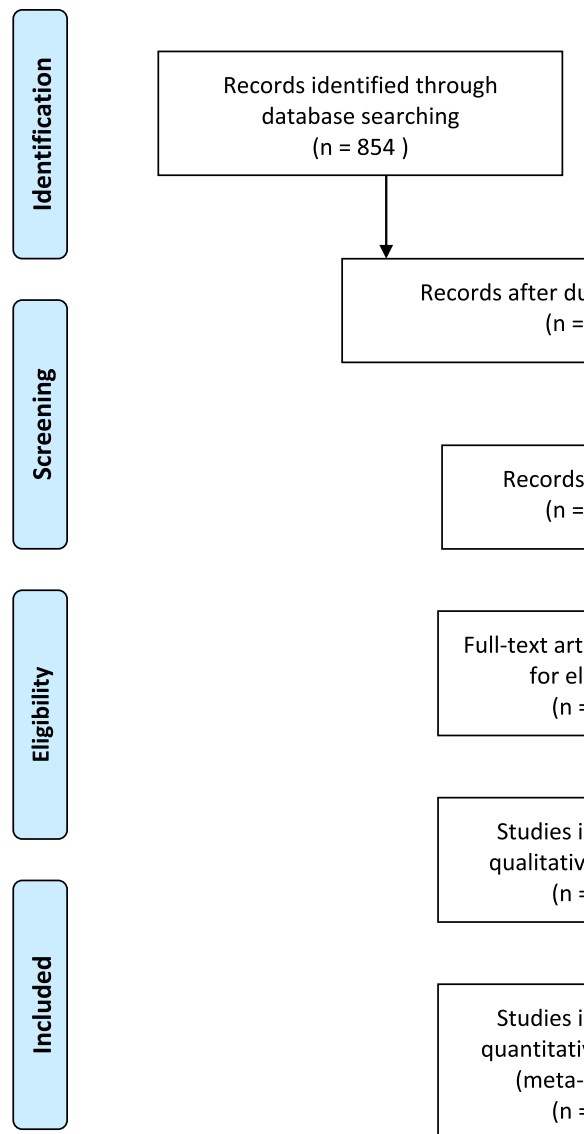

Additional records identified through other sources $(n=854)$ $(n=2)$

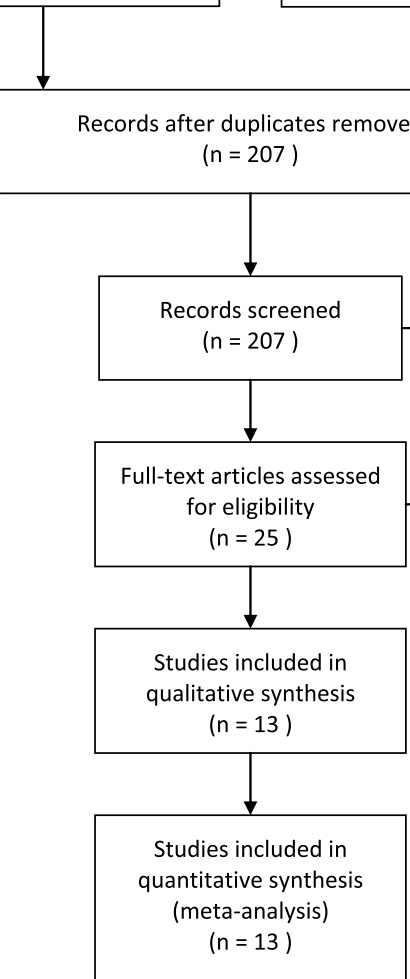

Fig. 1 Flow chart outlining the process of study identification, inclusion, and exclusion

Methodological quality evaluation revealed that seven trials $[13,32,33,35,36,38,40]$ had a low risk of bias, and the other six trials had a high or moderate risk. The risk of bias of included studies is demonstrated in Table 2.

\section{PRP versus CS}

In these 11 studies of the comparative efficacy of PRP and CS, 7 studies provided VAS scores for 6 months after injection and 4 studies provided an AOFAS score for 6 months after injection. After 6 months of follow-up, the combined effect of VAS and AOFAS was calculated and PRP was found to be superior to CS by calculating the pooled effect size of VAS and AOFAS respectively at the followup of 6 months (Fig. 2, MD $=-0.92, P<0.00001, I^{2}$ $=85 \%$; Fig. $3, \mathrm{MD}=10.05, P<0.00001, I^{2}=85 \%$ ). The sensitivity analysis failed to identify any trial that might lead to such statistical heterogeneity. We further analyzed the subgroup at different levels of VAS, as shown in Fig. 4 (low quality: $M D=-1.06$, $P<0.0001, I^{2}=91 \%$; high quality: $\mathrm{MD}=0.15, P=$ $0.72, I^{2}=1 \%$ ). Further, a subgroup analysis of different levels of AOFAS was performed, as shown in Fig. 5 (low quality: $\mathrm{MD}=11.22, P<0.0001, I^{2}=$ 87\%; moderate and high quality: $\mathrm{MD}=2.71, P=$ $\left.0.17, I^{2}=0 \%\right)$. No significant heterogeneity was observed in both high-quality and moderate-quality trials. For longer or shorter follow-up periods, most moderate- and/or high-quality trials had reported VAS and AOFAS scores within 3 and/or 12 months. After calculating the combined effect size, we found that PRP had no significant advantage during the follow-up period of 3 months and 12 months (VAS3 months: $\mathrm{MD}=-1.10, P=0.21, I^{2}=92 \% ; 12$ months: $\mathrm{MD}=-8.73, P=0.36, I^{2}=97 \%$; AOFAS- 


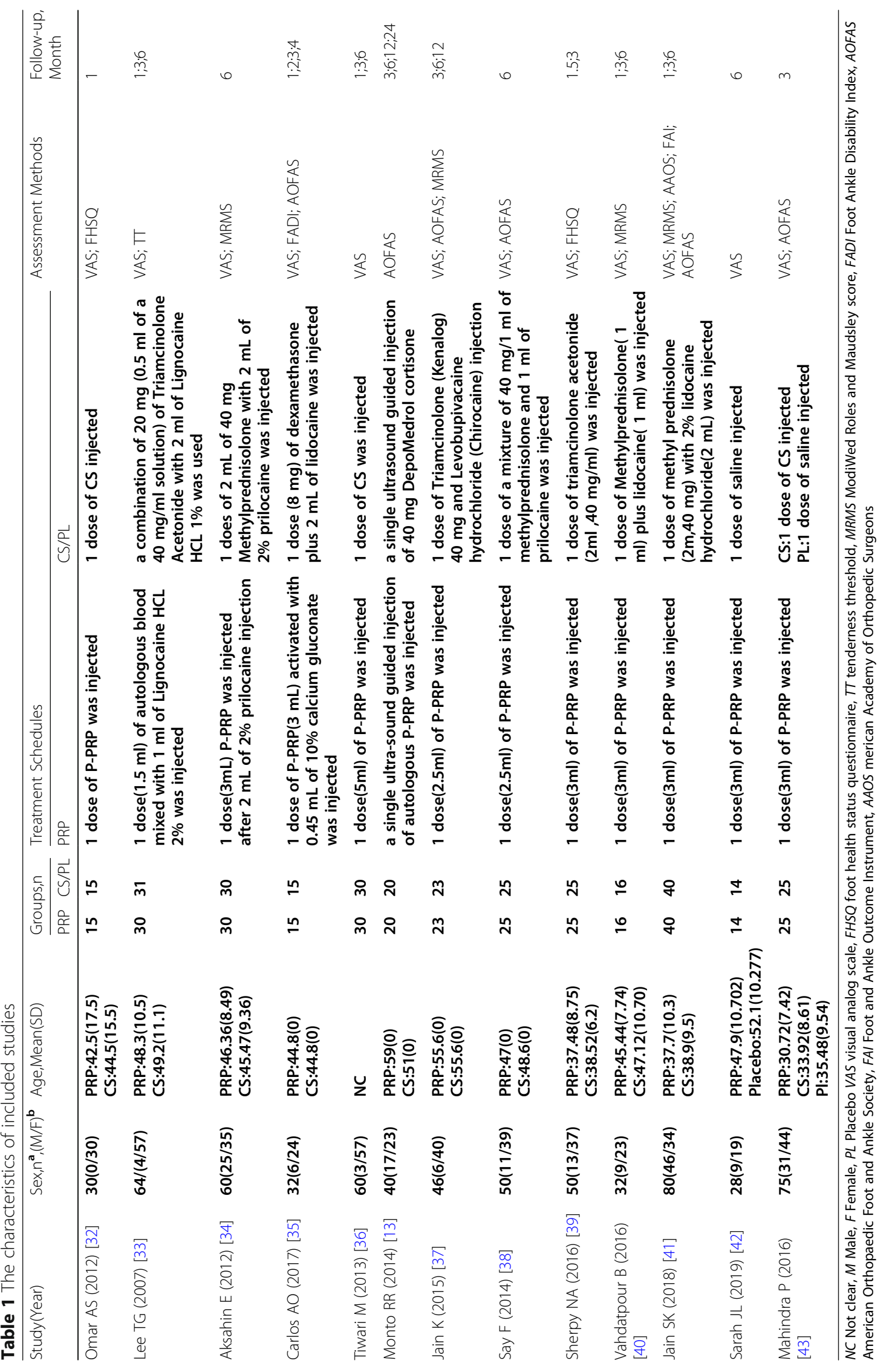


Table 2 The methodological quality of included RCTs

\begin{tabular}{|c|c|c|c|c|c|c|c|c|c|}
\hline Author(Year) & A & B & C & $\mathrm{D}$ & $E$ & $\mathrm{~F}$ & G & $\mathrm{H}$ & Overall Quality \\
\hline \multicolumn{10}{|l|}{ PRP Versus CS } \\
\hline Omar AS (2012) [32] & $\sqrt{ }$ & $x$ & $x$ & $x$ & $x$ & $x$ & $\mathrm{O}$ & $\mathrm{O}$ & Low \\
\hline Lee TG (2007) [33] & $\mathrm{O}$ & $x$ & $x$ & $\times$ & $x$ & $x$ & $\mathrm{O}$ & $\sqrt{ }$ & Low \\
\hline Aksahin E (2012) [34] & $\sqrt{ }$ & O & $\sqrt{ }$ & $\sqrt{ }$ & $\sqrt{ }$ & $x$ & $\sqrt{ }$ & $\sqrt{ }$ & High \\
\hline Carlos AO (2017) [35] & $\sqrt{ }$ & $x$ & $x$ & $\mathrm{O}$ & $x$ & $x$ & $\mathrm{O}$ & $\sqrt{ }$ & Low \\
\hline Tiwari M (2013) [36] & $\sqrt{ }$ & $x$ & $x$ & $\times$ & $x$ & $x$ & $\mathrm{O}$ & $\mathrm{O}$ & Low \\
\hline Monto RR (2014) [13] & $\sqrt{ }$ & $x$ & $x$ & $x$ & $\mathrm{O}$ & $x$ & $\mathrm{O}$ & $\sqrt{ }$ & Low \\
\hline Jain K (2015) [37] & $\sqrt{ }$ & $x$ & $\mathrm{O}$ & $x$ & $\sqrt{ }$ & $\mathrm{O}$ & $\sqrt{ }$ & $\sqrt{ }$ & Moderate \\
\hline Say F (2014) [38] & $\sqrt{ }$ & $x$ & $x$ & $x$ & $x$ & $x$ & $\sqrt{ }$ & $\mathrm{O}$ & Low \\
\hline Sherpy NA (2016) [39] & $\sqrt{ }$ & $\mathrm{O}$ & $x$ & $\times$ & $\sqrt{ }$ & $\sqrt{ }$ & $\sqrt{ }$ & $\mathrm{O}$ & Moderate \\
\hline Vahdatpour B (2016) [40] & $\sqrt{ }$ & $x$ & $\mathrm{O}$ & $\times$ & $x$ & $\times$ & $\mathrm{O}$ & $\mathrm{O}$ & Low \\
\hline Jain SK (2018) [41] & $\sqrt{ }$ & $\sqrt{ }$ & $\sqrt{ }$ & $\mathrm{O}$ & $\sqrt{ }$ & $\sqrt{ }$ & $\times$ & $\sqrt{ }$ & High \\
\hline \multicolumn{10}{|l|}{ PRP Versus PL } \\
\hline Sarah JL (2019) [42] & $\sqrt{ }$ & $\mathrm{O}$ & $x$ & $x$ & $\sqrt{ }$ & $\sqrt{ }$ & $\sqrt{ }$ & $\mathrm{O}$ & Moderate \\
\hline Mahindra P (2016) [43] & $\sqrt{ }$ & $\mathrm{O}$ & $\sqrt{ }$ & $\sqrt{ }$ & $x$ & $\sqrt{ }$ & $\sqrt{ }$ & $\sqrt{ }$ & High \\
\hline
\end{tabular}

A, adequate sequence generation; B, allocation concealment; C, blinding (participants); $D$, blinding (investigators); $E$, blinding (evaluators); $F$, incomplete outcome data inexistent or addressed; $G$, free of selective reporting; $H$, free of other bias

High, well-designed double-blind trials with proper allocation concealment and complete outcome data; Moderate: double-blind trials without proper allocation concealment or complete outcome data or single-blind trials; Low: trials without proper blinding methods applied.

The check mark $(\sqrt{ })$, yes; cross mark $(x)$, no; and circle $(O)$, unclear

3 months: $\mathrm{MD}=3.10, P=0.17, I^{2}=92 \% ; 12$ months: $\left.\mathrm{MD}=8.23, P=0.06, I^{2}=96 \%\right)$.

\section{PRP versus $\mathrm{PL}$}

Two studies comparing PRP and placebo were included in this meta-analysis [42, 43]. One article was judged to have an ambiguous bias risk; the other was found to be at a lower risk (Table 2). The pooled effect size of the VAS was calculated and is shown in Fig. $6\left(\mathrm{MD}=-3.76, P<0.00001, I^{2}=95 \%\right)$. Sensitivity analysis found no cause for heterogeneity. In addition, only one trial [43] using AOFAS as measurement had obviously revealed the beneficial effects of PRP.

\section{Discussion}

In this system review, we made a comprehensive evaluation of the efficacy of PRP comparing with CS or PL. By considering the therapeutic effects of all trials, we think that PRP is more effective than CS, but when only moderate- and/or high-quality literature was included for analysis, PRP had no obvious advantage. However, significant differences were found in the direct comparison between PRP and placebo. Thus, based on the best

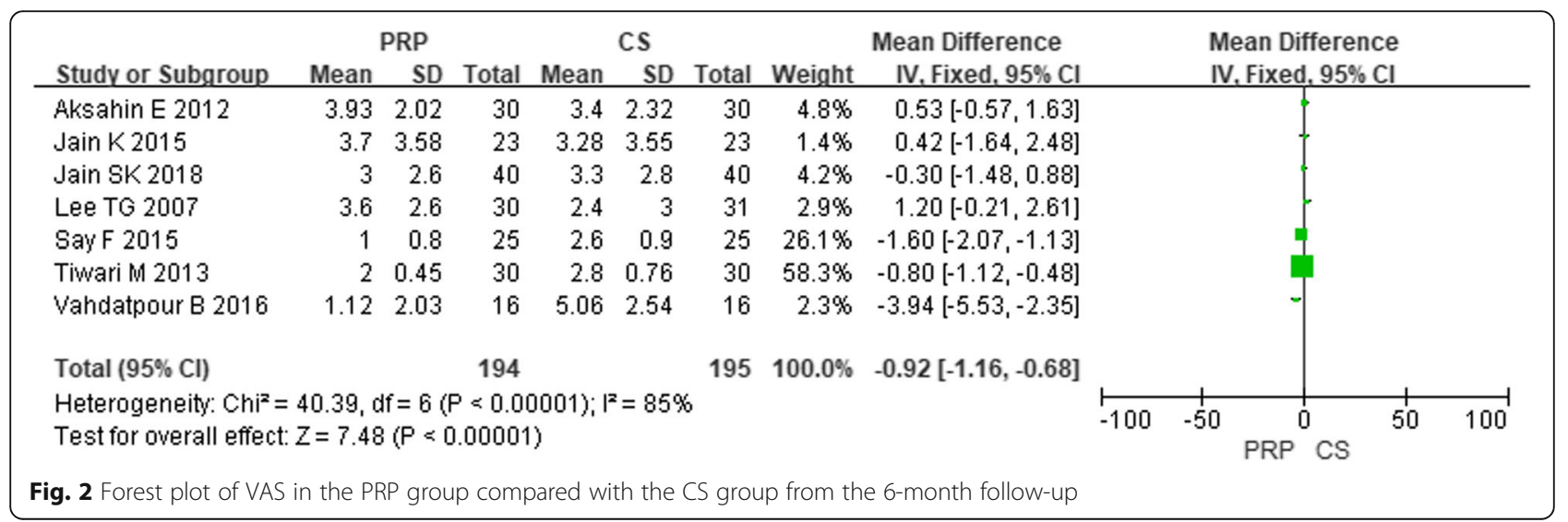




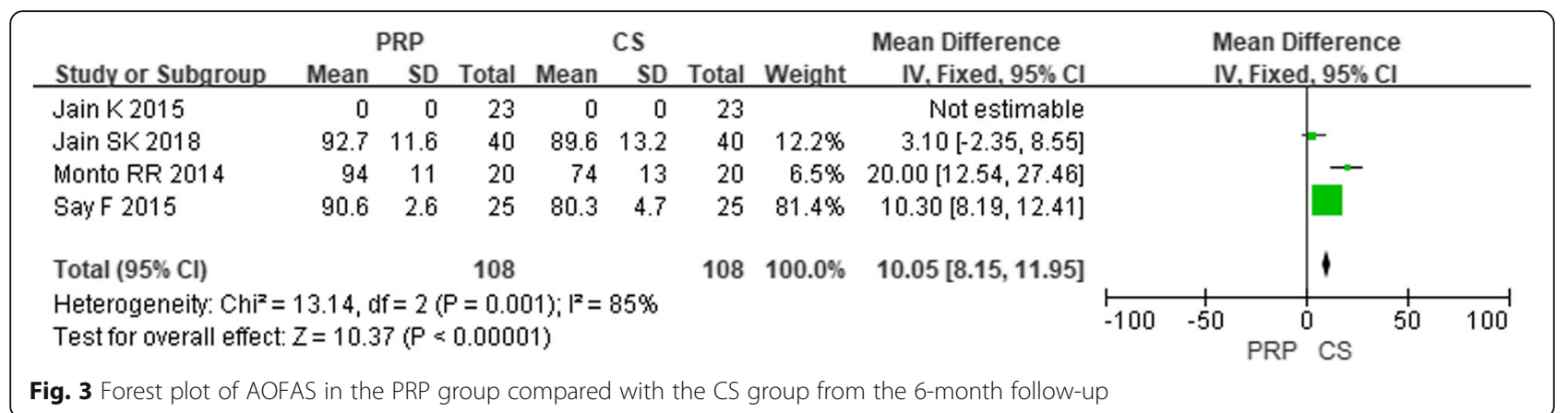

evidence, although PRP is not superior to CS in terms of pain relief and functional improvement, it is still considered more effective than placebo. With the application of best-evidence synthesis, the results of this study are not consistent with the conclusions of most previous meta-analysis [26-28]. In this study, we integrated all of the moderate- and/or high-quality randomized controlled trials on the efficacy of PRP in the treatment of $\mathrm{PF}$ and further explained more clearly the significance of the comparison of different interventions.

The good blind design of the study can play a key role in the assessment of the results of different interventions. Aksahin et al. [34] performed three blind experiments due to the difficulty in obtaining a different intra-group injection experience for blind operators. The studies of Jain et al. [41] and Mahindra et al. [43] that had relatively large sample size and used the blinding strategy for both participants and researchers were considered to be high-quality studies. Jain et al. [37] and Sherpy et al. [39] performed trials of different time in the patient, but the participants were not allowed to remain blind. Another experiment conducted by Johnson-Lynn et al. [42] performed a double-blind design, but its selective reporting and allocation of uncertainty concealment reduced the quality of the method. Because blind methods were not applied, the other trials were considered high risk of bias. Since the meta-analysis of the two high-quality tests did not produce the beneficial effect of PRP on CS and the homogeneity was high, it can be concluded that PRP may not be more effective than CS in relieving pain and improving function.

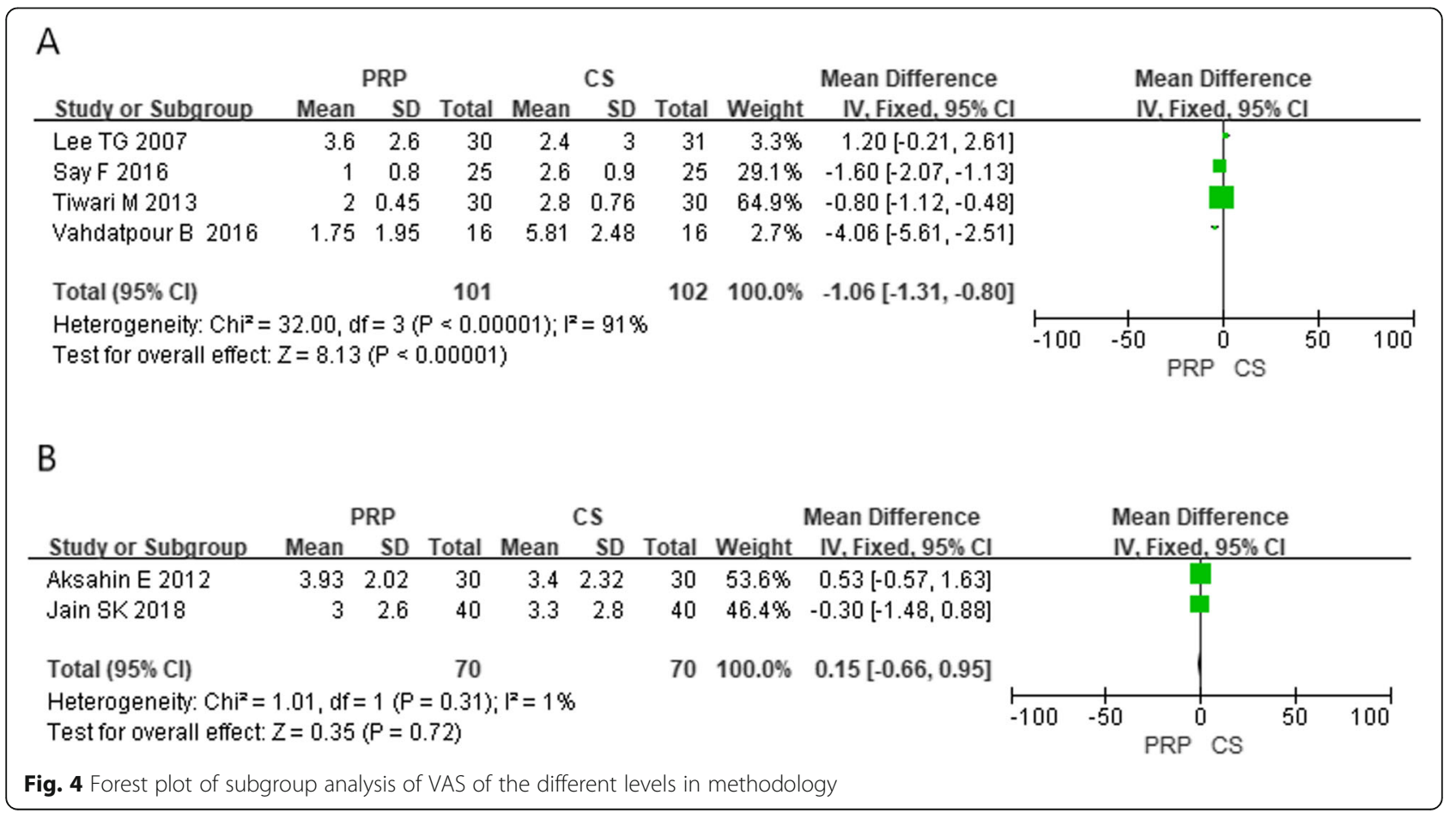




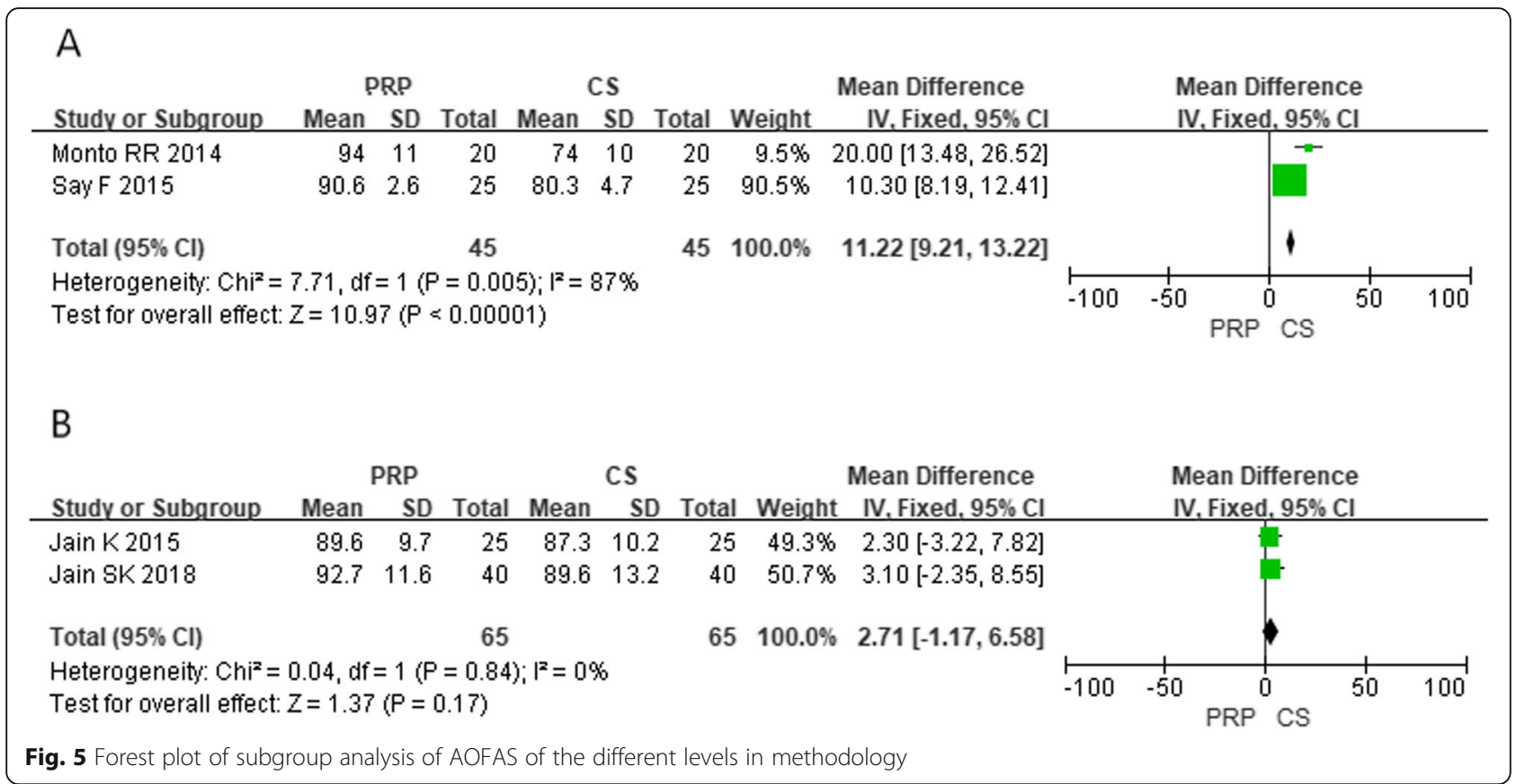

We all know that statistical heterogeneity can be reduced by accurate blind design, but heterogeneity will still exist in the final methodology, which is indeed a difficult problem. In different tests, the production of PRP and CS, as well as the dosage, time, and interval, was not completely consistent. In addition, differences in population, outcome scores, and disease duration may lead to high heterogeneity and different clinical outcomes. All these inconsistencies increase the difficulty of data synthesis and may lead to incorrect conclusions.

Just like other studies, our research also has some limitations. First of all, the number of included experiments with lower bias risk is relatively small, and because of the interference of external factors, it is impossible for literature searchers to retrieve all the experiments that may meet the requirements. Secondly, the current review focuses only on articles published in English. Inclusion in other languages may have an impact on heterogeneity and change current outcomes. In addition, the follow-up time of different studies was not consistent. In order to better verify the efficacy of PRP, a more large sample size of the strict randomized controlled trial needs to be further designed. Last but not least, limited by the reported results in included studies, this study only evaluated the VAS and AOFAS. Some other indicators were not analyzed. For instance, ultrasound is not only a diagnostic method but also a useful tool for monitoring response to treatments in patients with plantar fasciitis $[45,46]$. It can be included in the analysis in the future study when the relevant literature is sufficient.

\section{Conclusions}

In conclusion, in a well-designed double-blind trial, PRP did not show a better curative effect than CS, and in most of the researches, the advantage of PRP may be due to the lack of blind method. However, according to current evidence, PRP is still considered to be more effective than placebo.

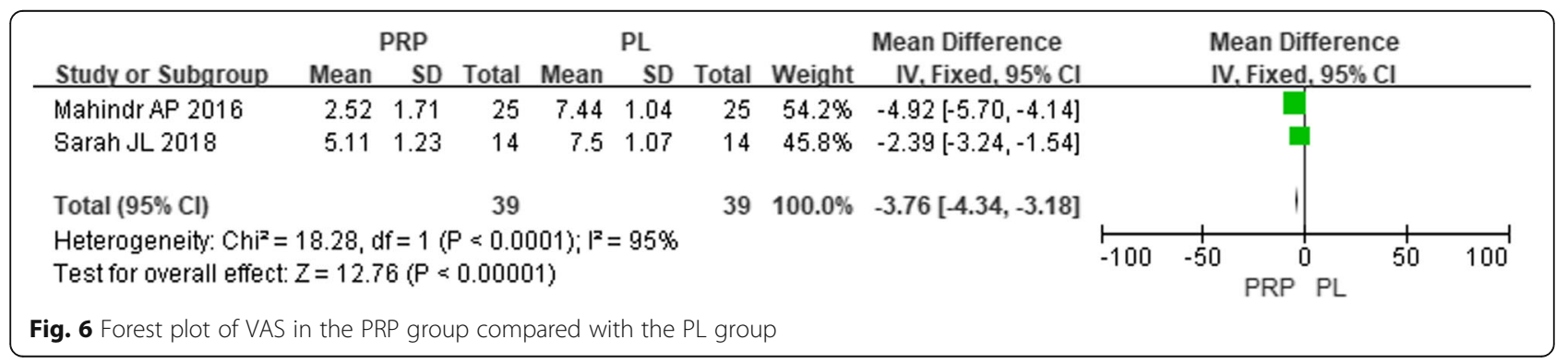




\section{Abbreviations}

PRP: Platelet-rich plasma; CS: Corticosteroid; PL: Placebo; NC: Not clear; M: Male; F: Female; VAS: Visual analog scale; FHSQ: Foot health status questionnaire; TT: Tenderness threshold; MRMS: ModiWed Roles and Maudsley score; FADI: Foot Ankle Disability Index; AOFAS: American Orthopaedic Foot and Ankle Society; FAl: Foot and Ankle Outcome Instrument; AAOS: American Academy of Orthopedic Surgeons

\section{Acknowledgements}

Thanks are due to Dr. Zaiyan Wang from Department of Respiratory Medicine, Shanghai University of Medicine \& Health Sciences Affiliated Zhoupu Hospital, Shanghai 201318, China, for assistance with the data analysis.

\section{Authors' contributions}

Tao Yu and Jiang Xia significantly contributed to the literature search, data selection, data analysis, and manuscript preparation. Bing Li participated substantially in the disagreement resolution. Haichao Zhou significantly contributed to the data organization and interpretation. Yunfeng Yang and Guangrong Yu contributed to the study design and manuscript revision. Al authors saw the original study data, reviewed the analysis of the data, and read and approved the final manuscript.

\section{Funding}

Our work was supported by the National Science Foundation of China (nos. 81472144 and 31600754).

\section{Availability of data and materials}

All data generated or analyzed during this study are included in this published article.

\section{Ethics approval and consent to participate}

This study did not need ethical approval, and consent from any patients involved in the study was also not needed.

\section{Consent for publication}

Not applicable.

\section{Competing interests}

The authors declare they have no competing interests

Received: 29 December 2019 Accepted: 2 July 2020

Published online: 21 September 2020

\section{References}

1. Monteagudo M, de Albornoz PM, Gutierrez B, Tabuenca J, Álvarez I. Plantar fasciopathy: a current concepts review. EFORT Open Rev. 2018;3(8):485-93.

2. Lynch DM, Goforth WP, Martin JE, Odom RD, Preece CK, Kotter MW. Conservative treatment of plantar fasciitis. A prospective study. J Am Podiatr Med Assoc. 1998;88(8):375-80.

3. Gross MT, Byers JM, Krafft JL, Lackey EJ, Melton KM. The impact of custom semirigid foot orthotics on pain and disability for individuals with plantar fasciitis. J Orthop Sports Phys Ther. 2002;32(4):149-57.

4. Böddeker R, Schäfer H, Haake M. Extracorporeal shockwave therapy (ESWT) in the treatment of plantar fasciitis--a biometrical review. Clin Rheumatol. 2001;20(5):324-30.

5. Buchbinder R, Ptasznik R, Gordon J, Buchanan J, Prabaharan V, Forbes A Ultrasound-guided extracorporeal shock wave therapy for plantar fasciitis: a randomized controlled trial. JAMA. 2002;288(11):1364-72.

6. Probe RA, Baca M, Adams R, Preece C. Night splint treatment for plantar fasciitis. A prospective randomized study. Clin Orthop Relat Res. 1999:368: $190-5$.

7. Powell M, Post WR, Keener J, Wearden S. Effective treatment of chronic plantar fasciitis with dorsiflexion night splints: a crossover prospective randomized outcome study. Foot Ankle Int. 1998;19(1):10-8.

8. DiGiovanni BF, Nawoczenski DA, Lintal ME, Moore EA, Murray JC, Wilding GE, Baumhauer JF. Tissue-specific plantar fascia-stretching exercise enhances outcomes in patients with chronic heel pain. A prospective, randomized study. J Bone Joint Surg Am. 2003;85(7):1270-7.
9. Basford JR, Malanga GA, Krause DA, Harmsen WS. A randomized controlled evaluation of low-intensity laser therapy: plantar fasciitis. Arch Phys Med Rehabil. 1998;79(3):249-54.

10. Landorf KB, Radford JA, Keenan AM, Redmond AC. Effectiveness of low-Dye taping for the short-term management of plantar fasciitis. J Am Podiatr Med Assoc. 2005;95(6):525-30.

11. Kamel $\mathrm{M}$, Kotob $\mathrm{H}$. High frequency ultrasonographic findings in plantar fasciitis and assessment of local steroid injection. J Rheumatol. 2000;27(9): 2139-41.

12. Marx RE. Platelet-rich plasma: evidence to support its use. J Oral Maxillofac Surg. 2004;62(4):489-96

13. Monto RR. Platelet-rich plasma efficacy versus corticosteroid injection treatment for chronic severe plantar fasciitis. Foot Ankle Int. 2014;35(4):313-8.

14. Shetty VD, Dhillon M, Hegde C, Jagtap P, Shetty S. A study to compare the efficacy of corticosteroid therapy with platelet-rich plasma therapy in recalcitrant plantar fasciitis: a preliminary report. Foot Ankle Surg. 2014;20(1): $10-3$.

15. Wilson JJ, Lee KS, Miller AT, Wang S. Platelet-rich plasma for the treatment of chronic plantar fasciopathy in adults: a case series. Foot Ankle Spec. 2014, $7(1): 61-7$

16. Kumar V, Millar T, Murphy PN, Clough T. The treatment of intractable plantar fasciitis with platelet-rich plasma injection. Foot (Edinb). 2013;23(2-3):74-7.

17. O'Malley MJ, Vosseller JT, Gu Y. Successful use of platelet-rich plasma for chronic plantar fasciitis. HSS J. 2013;9(2):129-33.

18. Kim E, Lee JH. Autologous platelet-rich plasma versus dextrose prolotherapy for the treatment of chronic recalcitrant plantar fasciitis. PM R. 2014;6(2): $152-8$.

19. Martinelli N, Marinozzi A, Carnì S, Trovato U, Bianchi A, Denaro V. Plateletrich plasma injections for chronic plantar fasciitis. Int Orthop. 2013;37(5): 839-42.

20. Peerbooms JC, van Laar W, Faber F, Schuller HM, van der Hoeven H, Gosens T. Use of platelet rich plasma to treat plantar fasciitis: design of a multi centre randomized controlled trial. BMC Musculoskelet Disord. 2010;11:69.

21. Ragab EM, Othman AM. Platelets rich plasma for treatment of chronic plantar fasciitis. Arch Orthop Trauma Surg. 2012;132(8):1065-70.

22. Li Z, Xia C, Yu A, Qi B. Ultrasound- versus palpation-guided injection of corticosteroid for plantar fasciitis: a meta-analysis. PLoS One. 2014;9(3):e92671.

23. Ball EM, McKeeman HM, Patterson C, Burns J, Yau WH, Moore OA, Benson C, Foo J, Wright GD, Taggart AJ. Steroid injection for inferior heel pain: a randomised controlled trial. Ann Rheum Dis. 2013;72(6):996-1002.

24. Lee HS, Choi YR, Kim SW, Lee JY, Seo JH, Jeong JJ. Risk factors affecting chronic rupture of the plantar fascia. Foot Ankle Int. 2014;35(3):258-63.

25. Brinks A, Koes BW, Volkers AC, Verhaar JA, Bierma-Zeinstra SM. Adverse effects of extra-articular corticosteroid injections: a systematic review. BMC Musculoskelet Disord. 2010;11:206.

26. Hsiao MY, Hung CY, Chang KV, Chien KL, Tu YK, Wang TG. Comparative effectiveness of autologous blood-derived products, shock-wave therapy and corticosteroids for treatment of plantar fasciitis: a network metaanalysis. Rheumatology (Oxford). 2015:54(9):1735-43.

27. Franceschi F, Papalia R, Franceschetti E, Paciotti M, Maffulli N, Denaro V. Platelet-rich plasma injections for chronic plantar fasciopathy: a systematic review. Br Med Bull. 2014;112(1):83-95.

28. Yang WY, Han YH, Cao XW, Pan JK, Zeng LF, Lin JT, Liu J. Platelet-rich plasma as a treatment for plantar fasciitis: a meta-analysis of randomized controlled trials. Medicine (Baltimore). 2017:96(44):e8475.

29. Singh P, Madanipour S, Bhamra JS, Gill I. A systematic review and metaanalysis of platelet-rich plasma versus corticosteroid injections for plantar fasciopathy. Int Orthop. 2017;41(6):1169-81.

30. Lodi G, Figini L, Sardella A, Carrassi A, Del FM, Furness S. Antibiotics to prevent complications following tooth extractions. Cochrane Database Syst Rev. 2012;11:CD003811.

31. Higgins JGSE. Cochrane Handbook for Systematic Reviews of Interventions Version 5.1.0. Int Orthop. 2011;2011:S38

32. Omar ASIME, Ahmed ASSM. Local injection of autologous platelet rich plasma and corticosteroid in treatment of lateral epicondylitis and plantar fasciitis: randomized clinical trial. Egypt Rheumatol. 2012:34(2):43-9.

33. Lee TG, Ahmad TS. Intralesional autologous blood injection compared to corticosteroid injection for treatment of chronic plantar fasciitis. A prospective, randomized, controlled trial. Foot Ankle Int. 2007;28(9):984-90.

34. Akşahin E, Doğruyol D, Yüksel HY, Hapa O, Doğan O, Celebi L, Biçimoğlu A. The comparison of the effect of corticosteroids and platelet-rich plasma 
(PRP) for the treatment of plantar fasciitis. Arch Orthop Trauma Surg. 2012 132(6):781-5.

35. Acosta-Olivo C, Elizondo-Rodriguez J, Lopez-Cavazos R, Vilchez-Cavazos F, Simental-Mendia M, Mendoza-Lemus O. Plantar fasciitis-a comparison of treatment with intralesional steroids versus platelet-rich plasma a randomized, blinded study. J Am Podiatr Med Assoc. 2017;107(6):490-6.

36. Tiwari M, Bhargava R. Platelet rich plasma therapy: a comparative effective therapy with promising results in plantar fasciitis. J Clin Orthop Trauma. 2013;4(1):31-5

37. Jain K, Murphy PN, Clough TM. Platelet rich plasma versus corticosteroid injection for plantar fasciitis: A comparative study. Foot (Edinb). 2015;25(4): 235-7.

38. Say F, Gürler D, İnkaya E, Bülbül M. Comparison of platelet-rich plasma and steroid injection in the treatment of plantar fasciitis. Acta Orthop Traumatol Turc. 2014:48(6):667-72.

39. Sherpy NAHMA, Hagrass HASH, Abu-EIMaaty SEMMA. Local injection of autologous platelet rich plasma compared to corticosteroid treatment of chronic plantar fas ciitis patients: a clinical and ultrasonographic follow-up study. Egypt Rheumatol. 2016;38(3):247-52.

40. Vahdatpour B, Kianimehr L, Moradi A, Haghighat S. Beneficial effects of platelet-rich plasma on improvement of pain severity and physical disability in patients with plantar fasciitis: a randomized trial. Adv Biomed Res. 2016;5: 179

41. Jain SK, Suprashant K, Kumar S, Yadav A, Kearns SR. Comparison of Plantar Fasciitis Injected With Platelet-Rich Plasma vs Corticosteroids. Foot Ankle Int. 2018:39(7):780-6.

42. Johnson-Lynn S, Cooney A, Ferguson D, Bunn D, Gray W, Coorsh J, Kakwani $\mathrm{R}$, Townshend $\mathrm{D}$. A feasibility study comparing platelet-rich plasma injection with saline for the treatment of plantar fasciitis using a prospective, randomized trial design. Foot Ankle Spec. 2019;12(2):153-8.

43. Mahindra P, Yamin M, Selhi HS, Singla S, Soni A. Chronic Plantar Fasciitis: Effect of Platelet-Rich Plasma, Corticosteroid, and Placebo. Orthopedics. 2016:39(2):e285-9.

44. Dohan EDM, Andia I, Zumstein MA, Zhang CQ, Pinto NR, Bielecki T. Classification of platelet concentrates (platelet-rich plasma-PRP, platelet-rich fibrin-PRF) for topical and infiltrative use in orthopedic and sports medicine: current consensus, clinical implications and perspectives. Muscles Ligaments Tendons J. 2014;4(1):3-9.

45. Moustafa AM, Hassanein E, Foti C. Objective assessment of corticosteroid effect in plantar fasciitis: additional utility of ultrasound. Muscles Ligaments Tendons J. 2015;5(4):289-96.

46. Petraglia F, Ramazzina I, Costantino C. Plantar fasciitis in athletes: diagnostic and treatment strategies. A systematic review. Muscles Ligaments Tendons J. 2017:7(1):107-18

\section{Publisher's Note}

Springer Nature remains neutral with regard to jurisdictional claims in published maps and institutional affiliations.

Ready to submit your research? Choose BMC and benefit from:

- fast, convenient online submission

- thorough peer review by experienced researchers in your field

- rapid publication on acceptance

- support for research data, including large and complex data types

- gold Open Access which fosters wider collaboration and increased citations

- maximum visibility for your research: over $100 \mathrm{M}$ website views per year

At $\mathrm{BMC}$, research is always in progress.

Learn more biomedcentral.com/submissions 